\title{
SABERES PROFISSIONAIS DO PROFESSOR QUE ENSINA GEOMETRIA: PROPOSTAS BELGAS NO RELATÓRIO DE LUIZ REIS (1892)
}

\author{
Gabriel Luís da Conceição \\ Maria Célia Leme da Silva 3
}

\section{RESUMO}

A presente investigação estuda os saberes profissionais do professor que ensina geometria, em circulação no Brasil, no final do século XIX. Em específico, busca-se caracterizar estes saberes nos relatos de Luiz Augusto dos Reis, professor brasileiro em missão pedagógica na Europa, especificamente na Bélgica. Assim sendo, pergunta-se: que saberes profissionais, para ensinar geometria nos primeiros anos escolares, podem ser caracterizados na análise dos registros de viagem do professor Luiz Reis? Para responder à questão, ampara-se nos estudos de Hofstetter e Schneuwly (2017) e utiliza-se, como fonte de investigação, o relatório de viagem produzido pelo docente. Pode-se dizer que Reis coloca em circulação, por meio de seu relatório, o que se espera

\footnotetext{
${ }^{1}$ Este artigo é resultado de pesquisa desenvolvida com auxílio da Fapesp. Agradecemos a leitura crítica e contribuições de Claudia Regina Boen Frizzarini na produção do artigo.

2 Universidade Federal de São Paulo (Unifesp), São Paulo/SP, Brasil.

3 Universidade Federal de São Paulo (Unifesp), São Paulo/SP, Brasil.
} 
do professor para o ensino de geometria no final do século XIX, um saber profissional em sintonia direta com as propostas do método intuitivo. As análises indicam uma alteração nos saberes a ensinar, outra ordem didático-pedagógica é recomendada. As mudanças no saber a ensinar articulam-se com a mobilização das ferramentas indicadas como saberes para ensinar, evidenciadas pelas atividades dos trabalhos manuais, de desenho, e das medidas. Está em jogo um novo saber profissional para o professor que ensina geometria, uma nova geometria para ensinar.

Palavras-chave: saberes profissionais, circulação internacional, saberes geométricos, escola primária.

\section{SABERES PROFESIONALES DEL PROFESOR QUE ENSEÑA GEOMETRÍA: PROPUESTAS BELGAS EN EL INFORME DE LUIZ REIS (1892)}

\section{RESUMEN}

La presente investigación estudia los saberes profesionales del profesor que enseña geometría en circulación en Brasil a finales del siglo XIX. En concreto, se busca caracterizar estos saberes en los relatos de Luiz Augusto dos Reis, profesor brasileño en misión pedagógica en Europa, más específicamente en Bélgica. Así pues, se pregunta, ¿qué saber profesionales para enseñar geometría en los primeros años escolares pueden ser caracterizados en el análisis de los registros de viaje del profesor Luiz Reis? Para responder a la cuestión, se ampara en los estudios de Hofstetter y Schneuwly (2017) y se utiliza como fuente de investigación el informe de viaje producido por el docente. Se puede decir que Reis pone en circulación, por medio de su informe, lo que se espera del profesor para la enseñanza de geometría a finales del siglo XIX, un saber profesional en sintonía directa con las propuestas del método intuitivo. Los análisis indican una alteración en los saberes a enseñar, otro orden didáctico-pedagógico es recomendable. Los cambios en el saber a enseñar se articulan con la movilización de las herramientas indicadas como saberes para enseñar, evidenciadas por las actividades de los trabajos manuales, de diseño, y de las medidas. Está en juego un nuevo saber profesional para el profesor que enseña geometría, una nueva geometría para enseñar.

Palabras clave: saberes profesionales, circulación internacional, saberes geométricos, escuela primária.

\section{PROFESSIONALS KNOWLEDGE OF THE GEOMETRY TEACHER: BELGIAN PROPOSALS IN LUIZ REIS' REPORT (1892)}

\section{ABSTRACT}

The present research studies the profissional knowledge of the teacher who teaches geometry in circulation in Brazil in the late nineteenth century. Specifically, the aim is to characterize this knowledge in the accounts of Luiz Augusto dos Reis, a Brazilian teacher in pedagogical mission in Europe, specifically in Belgium. Thus, it is asked, which professional knowledge for teach 
geometry in the first years of school can be characterized in the analysis of the travel records of teacher Luiz Reis? To answer the question, it is based on the studies of Hofstetter and Schneuwly (2017) and uses as a research source the trip report produced by the teacher. It can be said that Reis puts into circulation, through his report, what is expected of the teacher for the teaching of geometry in the late nineteenth century, a professional knowledge in line with the proposals of the intuitive method. The analyses indicate a change in the knowledge to teach, another pedagogical-didact order is recommended. The changes in the knowledge to teach articulated with the mobilization of the indicated tools like knowledge for teach, evidenced by the activities of the manual works, of drawing, and of the measures. At stake is a new professional knowledge for the teacher who teaches geometry, a new geometry for teaching.

Keywords: professional knowledge, international circulation, geometric knowledge, elementary school.

\section{SAVOIRS PROFESSIONNELS DE L'ENSEIGNANT QU'ENSEIGNE GEOMETRIE: PROPOSITIONS BELGES DANS LE RAPPORT DE LUIZ REIS (1892)}

\section{RÉSUMÉ}

La présente recherche étudie les savoirs professionnels de l'enseignant qui enseigne la géométrie en circulation au Brésil à la fin du XIXe siècle. Plus précisément, l'objectif est de caractériser ces savoirs dans les rapports de Luiz Augusto dos Reis, enseignant brésilien en mission pédagogique en Europe, plus particulièrement en Belgique. Ainsi, cet article interroge, quels savoirs professionnels pour enseigner la géométrie dans les premières années d'école puissent être caractérisées dans l'analyse des rapports de voyage du professeur Luiz Reis ? Pour répondre à la question, on s'appuie sur les études de Hofstetter et Schneuwly (2017) et on utilise comme source de recherche le rapport de voyage produit par l'enseignant. On peut dire que Reis met en circulation, à travers son rapport, ce que l'on attend de l'enseignant pour l'enseignement de la géométrie à la fin du XIXe siècle, un savoir professionnel conforme des propositions de la méthode intuitive. Les analyses indiquent un changement dans les savoirs à enseigner, une autre commande pédagogique-didactique est recommandée. Les changements dans les savoirs à enseigner s'articulent avec la mobilisation des outils indiqués comme savoirs pour enseigner, mis en évidence par les activités des travaux manuels, du dessin et des mesures. L'enjeu est un nouveau savoir professionnel pour l'enseignant qui enseigne la géométrie, une nouvelle géométrie à enseigner.

Mots-clés: savoir professionnel, circulation international, savoirs géométriques, école primaire. 


\section{INTRODUÇÃO}

Se a Italia é a terra da arte, como a França, que é, nesse ponto, a sua poderosa rival; se a Inglaterra é o paiz das poderosas esquadras e do ouro, que nunca é bastante para ser capaz de saciar-lhe as ambições desmedidas; a Bélgica é a terra da instrução popular, o paiz da manufactura e das escolas bem organizadas, um dos paizes europeus em que mais e melhor se cultiva a sciencia pedagógica (REIS, 1892, p. 336).

O extrato revela o contexto europeu do final do século XIX, no qual o contato com as atualizações no campo educacional era feito por viagens pedagógicas internacionais. Segundo Matasci (2015), tratava-se de uma das principais formas da circulação internacional de ideias pedagógicas no recorte temporal deste estudo, um tempo de valorização e circulação de propostas educacionais, advindas de várias partes do mundo.

Considera-se a importância da circulação de propostas e pessoas no âmbito cultural, compreendendo o movimento não como "importação" de modelos, nem como distorção dos originais, mas como reconstruções de significados, produzindo uma "representação" 4 , uma nova originalidade (VIDAL, 2005).

A proposta deste artigo está em caracterizar os saberes profissionais dos professores que ensinam geometria, postos em circulação no Brasil, sobre o cenário educacional belga no final do século XIX. A análise é realizada a partir das representações do brasileiro Luiz Augusto dos Reis publicadas em seu relatório de viagem após retorno da missão pedagógica para a qual foi enviado à Europa.

Os saberes profissionais, conceito que sustenta a análise das fontes, são entendidos como aqueles que personalizam o profissional da docência no

\footnotetext{
${ }^{4}$ As representações são "as matrizes de discursos e de práticas diferenciadas [...] que têm por objetivo a construção do mundo social e, como tal, a definição contraditória das identidades" (CHARTIER, 2002, p. 18).
} 
presente estudo, isto é, o professor que ensina geometria, ou seja, os saberes necessários para sua ação, mobilizados no ato pedagógico, os saberes da ação. Considerar-se-á os saberes produzidos, sistematizados e institucionalizados, que vão, ao longo do tempo, se objetivando, tornando-se referência na profissionalização docente (VALENTE, 2016).

A pesquisa, em conformidade com os estudos da Equipe de Pesquisa em História das Ciências da Educação5, elege duas categorias de saberes que se articulam na profissionalização de professores, e que integram o saber profissional. De um lado, os saberes para ensinar, saberes constitutivos do campo profissional, nos quais a referência é a expertise ${ }^{6}$ profissional e, de outro lado, saberes a ensinar, saberes emanados dos campos disciplinares de referência produzidos pelas disciplinas universitárias (HOFSTETTER; SCHNEUWLY, 2017).

Desse modo, a problemática do estudo se apresenta como: que saberes profissionais para ensinar geometria nos primeiros anos escolares podem ser caracterizados na análise dos registros de viagem do professor Luiz Augusto dos Reis? Para responder à questão, toma-se como fonte o relatório7 oficial produzido após viagem em missão pedagógica à Europa, em especial sobre suas representações acerca do ensino primário belga de geometria.

\section{A “COMISSÃO DE 1891": O PROFESSOR LUIZ AUGUSTO DOS REIS E A BÉLGICA}

\footnotetext{
5 ERHISE: Equipe de Recherche en Histoire des Sciences de l'Éducation. Grupo de pesquisa coordenado pelos professores suíços Rita Hofstetter e Bernard Schneuwly. Mais informações em: https://cms.unige.ch/fapse/SSE/erhise/

${ }^{6}$ A expertise relaciona-se a "uma instância, em princípio reconhecida como legítima, atribuída a um ou a vários especialistas - supostamente distinguidos pelos seus conhecimentos, atitudes, experiências -, a fim de examinar uma situação, de avaliar um fenômeno, de constatar fatos. Esta expertise é solicitada pelas autoridades do ensino, tendo em vista a necessidade de tomar uma decisão e participa poderosamente da produção de novos saberes no campo pedagógico" (HOFSTETTER, SCHNEUWLY, 2017, p. 57).

7 Publicado pela Imprensa Nacional: REIS, Luiz Augusto dos. O ensino público em Portugal, Espanha, França e Bélgica. Rio de Janeiro: Imprensa Nacional, 1892.
} 
De acordo com Gondra (1997), no final do século XIX, o museu Pedagogium ${ }^{8}$, estava recrutando "destacados professores" para missões pedagógicas, reforçando o movimento internacional de ações educacionais estudados por Matasci (2015). Em missão de estudo, com destino a outros países, professores saíram em busca de distintas experiências, com base na abordagem da missão, que era uma "técnica de investigação e conhecimento, como prática de observar, experimentar, comparar e produzir conhecimento sobre o outro" (GONDRA, 2010, p. 13).

Diversas pesquisas ${ }^{9}$ de cunho historiográfico investigaram a temática "viagens pedagógicas" sob perspectivas e abordagens diferenciadas. Em suma, os estudos chegaram a conclusões de que as propostas educacionais europeias e estadunidenses constituíram-se como parâmetros para o ensino no Brasil no final do século XIX.

Neste tempo, as viagens pedagógicas intencionavam, também, à aproximação de políticas educacionais, bem como às práticas de ensino inovadoras e bem-sucedidas; a estratégia era quase global. Assim, vários países interessavam-se em enviar educadores com esta finalidade (MIGNOT; GONDRA, 2007).

Os relatos produzidos pelos viajantes são construções ideológicas e sociais, dessa forma, deve-se considerar o seu contexto históricosocial, as condições de reprodução tal como nos propõe a História Cultural. Eles foram produzidos e publicados com uma

\footnotetext{
8 Trata-se de um museu pedagógico fundado em 1890 no Rio de Janeiro que, neste tempo, era reconhecido como o Distrito Federal. Em 1897, foi transformado em um centro de cultura superior e, em 1906, recebeu o primeiro laboratório de psicologia experimental do país. Foi extinto em 1919 pelo Decreto Municipal n. 1360. Tinha por objetivo ser um centro impulsionador das reformas educacionais, oferecendo formação e atualização dos professores. Assim, o museu contava com as seguintes tarefas: realizar conferências e cursos científicos, ter gabinetes de ciências, realizar exposições escolares anuais, dirigir a Revista Pedagógica (mantida entre 1890 e 1897), adquirir livros, revistas, aparelhos, mobiliários e instrumentos pedagógicos, manter uma escola-modelo, manter uma biblioteca circulante, levantar dados sobre a realidade escolar do país e, principalmente, tinha como objetivo a disseminação de museus escolares nos estados a fim de ampliar o método das lições de coisas (BASTOS, 2002).

9 Destacam-se os trabalhos de Schueler e Gondra (2010), Chamon (2005), Pimenta (2008), Araújo (2010), Fonseca (2010), Pinto (2011), Cardoso (2015) e Rabelo (2016).
} 
intencionalidade, os relatores pretendiam compartilhar experiências, valorizar e difundir iniciativas de um modelo educativo. Eles apresentam transformações educacionais e uma nova cultura escolar compartilhada mundialmente. Trazem à tona - mesmo que seja dos seus pontos de vistas - características dos espaços escolares, métodos educativos, programas escolares, o ideal de professor e aluno valorizados naquele momento (CARDOSO, 2015, p. 37, grifos nossos).

Mignot e Gondra (2007) indicam que as viagens vinham sendo realizadas por educadores do Brasil, da Espanha, de Portugal, da França, Alemanha, Suíça, Bélgica, Japão, além de muitos outros países, e que se deslocaram a lugares próximos ou distantes com a mesma finalidade, aprender com o "outro".

A "Comissão de 1891" foi a primeira comissão oficial republicana de professores brasileiros em viagem ao exterior designada à Europa em 28 de outubro de 1890 (SCHUELER; GONDRA, 2010). Contava com os docentes primários Luiz Augusto dos Reis, Manoel José Pereira Frazão e Amélia Fernandes da Costa que circularam por Portugal, Espanha, França, Suíça, Suécia, Bélgica e Inglaterra.

Os membros da comissão distinguiam-se daqueles que viajam por "puro prazer ou amor à cultura". Viajavam na e pela condição de professor, cabendo-lhes uma série de atribuições e encargos que outros viajantes não enfrentavam. Profissionais comissionados deveriam visitar as escolas, observar e estudar os métodos, técnicas e arquitetura de locais de ensino, escrever relatórios descrevendo tudo, além de remeter os materiais e objetos interessantes para o ensino no Brasil. Tais atribuições sugerem pensar a viagem em missão oficial como parte de uma troca entre os envolvidos, no sentido de dom e contradom, uma vez que, se, por um lado, recebia-se financiamento e custeio de hospedagem e deslocamentos, por outro, havia uma série de obrigações e encargos, no sentido de retribuir aqueles que financiavam a viagem (MIGNOT; SILVA, 2011, p. 437, grifos nossos).

Vale ressaltar que a Revista Pedagogica ${ }^{10}$ destacou o retorno destes

${ }^{10}$ Trata-se do primeiro periódico especializado em questões educacionais financiado pelo poder 
professores às salas de aula, reconhecendo o trabalho e a expertise profissional adquirida de cada um, assim como, foi um importante veículo que fez circular os relatos de propostas internacionais produzidos pelos viajantes para os professores brasileiros.

\begin{abstract}
É provável que as escolas dos professores D. Amelia Fernandes da Costa, Manoel José Pereira Frazão e Luiz Augusto dos Reis comecem este ano a trabalhar em condições que permitam ser executados os melhores méthodos e processos de ensino, estudados por esses distintos colegas em sua recente e proveitosa excursão pela Europa. No ponto de vista material e pedagógico servirão de modelo ao nosso professorado publico e particular (REVISTA PEDAGOGICA, 1895, p. 291).
\end{abstract}

$\mathrm{Na}$ análise dos relatórios de viagem, Luiz Augusto dos Reis faz questão de mencionar o pouco tempo, apenas alguns dias, que esteve na Bélgica, podendo visitar poucas escolas"11, mas afirma que "este tempo, garanto, foi bem aproveitado" e que por estas razões, concentrou principalmente a atenção na escola anexa à escola Normal, que é a escola modelo ${ }^{12}$, e no Museu Pedagógico daquele país, informando que, "as escolas belgas, afirmo sem receio de contestação, são um verdadeiro primor, qualquer que seja o ponto de vista pedagogico por que as encare" (REIS, 1892, p. 334).

Reis enfatiza em seus registros que em finais do século XIX, a Bélgica era reconhecida internacionalmente como o país com as escolas de "mais alta reputação em todo o mundo civilizado" e, ainda, como o "paiz das boas escolas, o paiz em que o ensino popular é a causa de todos os cidadãos, é a grande causa nacional", enfim "um dos países Europeus em que mais e melhor se cultiva a

público republicano, e que circulou entre 1890 e 1896. Destacam-se os estudos de Gondra (1996; 1997).

${ }^{11} \mathrm{O}$ roteiro de Reis foi constituído das seguintes visitas: (1) Escola Normal e Escola de Aplicação e Anexos, situada no Boulevard du Hainaut, 98; (2) Escola Primária n. 3 (sexo masculino); Rue Nouveaux Marché aux Grains; (3) Jardim de Infância n. 7, rue de la Roue; e (4) Jardim de infância n. 5, rue des Fleuristes.

12 Escola modelo é uma escola anexa à Escola Normal destinada à prática de seus alunosmestres. Funcionou como um campo de experimentação do ensino e centro de irradiação de novos métodos de ensino (SOUZA, 2009). 
sciencia pedagógica" (REIS, 1892, p. 336).

Mas afinal, quem era o professor Luiz Augusto dos Reis? Segundo Blake (1899), Reis iniciou sua carreira docente na escola pública da Gávea, no Rio de Janeiro, em 1870, sendo inicialmente professor adjunto, efetivando-se em 1873 "de acordo com o relatório do Inspetor Geral de 1873. Em junho desse mesmo ano, Luiz Reis foi aprovado nos exames de capacitação ao magistério e, por aviso de 31/07/1873, foi considerado habilitado para o magistério primário da Corte" (PINTO, 2011, p. 32).

Pinto (2011) ainda afirma que o referido professor exerceu o magistério de 1870 a 1895 de forma exemplar, dedicando os seus anos na instrução primária, destacando-se dos demais professores do então Distrito Federal, sendo atuante nos debates educacionais de sua época. Sua ação pedagógica sempre foi ativa, e esta expertise pode ter contribuído para que fosse um dos escolhidos a compor o grupo de professores que representariam o Brasil na “Comissão de 1891" para a Europa.

\section{OS SABERES PROFISSIONAIS DO PROFESSOR QUE ENSINA GEOMETRIA: PROPOSTAS BELGAS}

Luiz Augusto dos Reis, em seus registros de viagem, relatou grande quantidade de referências sobre a cultura escolar europeia ${ }^{13}$, descreveu, desde a arquitetura e o formato das salas e mobílias, até métodos pedagógicos, legislações, programas, livros e autores, mas o que ele registrou acerca dos saberes profissionais dos docentes que ensinavam geometria na Bélgica?

Como exposto no tópico anterior, o ensino belga, naquele tempo, era compreendido como um espaço de estruturação nacional. Nesses moldes, o currículo do curso primário, nesse país, era caracterizado por:

${ }_{13}$ Sua missão pedagógica perpassou por Portugal, Espanha, Itália, França e Bélgica. 
leitura, escripta, calculo, systema legal de pesos e medidas, elementos de língua franceza, flamenga ou allemã, conforme as necessidades locaes, geografia, historia da Belgica, desenho, canto e gymnastica, noções de agricultura para os meninos e trabalho de agulha para as meninas [...] cursos de trabalhos manuais para os rapazes, e destinados a desenvolver a destreza da mão, podem ser anexos aos cursos primarios (REIS, 1892, p. 377).

E o objetivo central se baseava no "desenvolvimento da creança no conjunto de suas faculdades [...] e a provocar incessantemente a espontaneidade do pensamento" (p. 381), marcas do método pedagógico internacional em voga, o método intuitivo ${ }^{14}$. Entre as inovações vinculadas a este método destaca-se o ensino de coisas vinculadas à vida, aos objetos e fatos presentes no cotidiano das crianças; a introdução de objetos didáticos como elementos imprescindíveis à formação das ideias, por seu caráter lúdico, mas também disciplinador: um elemento novo em sala de aula, que guia o caminho do conhecimento unindo a classe de alunos e o professor. O método traz ainda "a possibilidade de uniformizar raciocínios, modos de pensar, cristalizando uma forma de apropriação das coisas exteriores num processo que é dirigido pelo professor, o representante naquela situação do legado das gerações precedentes, inclusive com seus valores e seus preconceitos” (VALDEMARIN, 2004, p. 176).

Dessa forma, Luiz Reis relata que o ensino das matérias que compunham o programa,

[...] não poderia ser apresentado pelo professor pela forma puramente expositiva ou por simples leituras. Ellas devem ser ensinadas por exercícios intuitivos que ponham constantemente em jogo a atividade da creança. A creanca deve ser colocada, tanto quanto possível, em presença das cousas que fazem o objeto da licçao. Ella as observa e analysa, guiada pelo professor (REIS, 1892, p. 381, grifos nossos).

\footnotetext{
14 Método de ensino que surgiu na Alemanha no final do século XVIII. Foi divulgado pelos seguidores de Pestalozzi no decorrer do século XIX na Europa e nos Estados Unidos. No Brasil, fez parte das propostas de reformulação da instrução pública no final do Império, tendo Rui Barbosa como um dos principais defensores (VALDEMARIN, 2004).
} 
Ainda a partir do relato de Reis, verifica-se que a geometria não compõe o currículo primário belga como uma matéria escolar. Entretanto, é exposta como um dos eixos do ensino das "mathematicas":

[...] o ensino das mathematicas terá por base a geometria e o calculo mental. A geometria é ensinada pelo estudo dos corpos geométricos; os alumnos os observam, e o professor lhes faz compreender os termos; ensina-lhes as noções de grandezas, da sua comparaçao, da proporção, da symetria, da equivalência. Os teoremas mais importantes são demonstrados por exercícios intuitivos.

O systema métrico é ensinado pela experiência real das medidas. Os alumnos calculam as superfícies e os volumes medindo por si mesmos as dimensões e não operando sobre dados imaginários (REIS, 1892, p. 382 , grifos nossos).

Mesmo sem constituir-se como uma matéria em separado, a geometria insere-se na proposta do ensino de matemática belga, evidencia sua forte relação com as formas geométricas, e revela marcas explícitas da proposição do método intuitivo, como sugerido nas atividades de observação, comparação e experiência real. Ou seja, a proposta de ensino vincula-se às atividades práticas.

E, em específico, para o ensino de geometria nas "mathematicas" belgas, Reis realça que o ensino dos modelos geométricos era feito com muito cuidado, de forma que o professor deveria obedecer seis passos, transcritos na íntegra:

Primeiro passo: As fórmas geométricas são ensinadas especialmente com o fim de exercitar os sentidos e a intellingência e de fornecer aos alumnos noções praticas e uteis. O professor procede, por consequência, fazendo observar, analysar e comparar as fórmas geométricas, materialmente representadas em madeira, em cartão ou com auxilio de bastonetes, etc. A observação não pode fazer-se unicamente pela vista, que, pelo efeito da perspectiva, não fornece senão noções inexactas sobre as fórmas, as dimensões, as distâncias; os alumnos percebem as fórmas, as dimensões, as direções, etc., pelo toque e o sentido muscular, que rectificam as impressões da vista. Elles devem, pois, manejar e construir as fórmas pelos processos 
colhidos no methodo Froebel15 (modelação, bastonetes, dobradura, corte, cartonagem, desenho).

Segundo passo: Os alumnos são exercitados em procurar os objetos comuns nos quaes cada fórma estudada se apresenta exatamente mais ou menos modificada. Exemplos: Cylindro (lápis, caneta, rolo de papel, caixas, tubos de gaz, vidros de lampeão, etc.). É útil formar, com o concurso dos alumnos, em cada classe, a coleção dos modelos pertencentes ao programa dessa classe.

Terceiro passo: "As aplicações dos modelos geométricos nos officios são indicadas tão completamente quanto possível”.

Quarto passo: O caracter do ensino dos modelos geométricos deve ser essencialmente intuitivo e pratico: as definições difíceis e as demonstrações scientificas não são dadas. Entretanto, os alumnos são exercitados em descrever de viva voz as figuras estudadas, primeiro que tudo em presença dos modelos e apoz de memoria. Essas descripções são exercícios de educação especialmente recomendados, porque dão precisao ao pensamento e a linguagem.

Quinto passo: As figuras geométricas servem para ensinar as fórmas ou as propriedades das que devem ser traçadas correctamente no quadro negro, por meio de instrumentos. É observando e construindo figuras exactas, combinando-as, superpondo-as, examinando suas relações, que os alumnos acharão por si mesmos toda a geometria elementar, sem que ella seja questão de definições, de teoremas, de corolários, etc. A superposição de figuras correctamente construídas é o modo de demonstração por excellencia no ensino primário. Ella se faz em todas as classes com o auxilio do processo de corte ensinado no programma de trabalhos manuais.

Sexto passo: Os dictados geométricos se fazem em todas as classes, uma vez por semana. Os alumnos traçam as figuras dictadas sobre os quadros negros que circumdam a sala. Naquellas que não possuem ainda estes utensis de ensino, eles os traçam sobre a carteira (a giz) na ardósia ou no papel (a lápis) (REIS, 1892, p. 461-462, grifos nossos).

Pode-se identificar, no conjunto de passos ao ensino dos modelos geométricos, indícios de saberes profissionais para a docência. O ensino é mobilizado pelo professor, que acompanha os alunos na observação, análise e comparação das formas geométricas. Destaca-se, na descrição dos passos, que a observação não deve se restringir à vista; enfatiza-se a necessidade de tocar,

15 Os brinquedos de Froebel, dons ou trabalhos froebelianos são materiais formulados pelo próprio Froebel, constituídos por sólidos geométricos, gravuras coloridas e trabalhos manuais que propiciavam exercícios sensoriais e motores (BASTOS, 2011). 
manejar, construir as formas geométricas. Em outras palavras, evidencia-se uma prática ativa dos alunos na produção e manipulação dos objetos.

Os seis passos para o ensino de modelos geométricos belga destacam a articulação dos saberes profissionais docentes, o saber a ensinar, com ligação às ciências, com o campo disciplinar do saber e, assim, compõem objeto de trabalho do professor; e o saber para ensinar, ferramentas mobilizadas pelo campo pedagógico na prática da profissão do ensino.

Verifica-se no relatório de Reis que os saberes a ensinar deveriam ser articulados aos saberes para ensinar em seis passos, como exposto acima, e indicavam a observação não só pela vista, mas com o toque e o sentido muscular, além das construções pelo método Froebel (primeiro passo); a associação dos modelos geométricos aos objetos comuns (segundo passo); aplicações aos ofícios (terceiro passo); descrição das figuras em voz alta (quarto passo); o ensino das figuras geométricas sem as formalizações, definições, teoremas, mas com a superposição de figuras com o auxílio dos trabalhos manuais por meio do corte (quinto passo) e pelos ditados geométricos, onde os alunos constroem as figuras ditadas à mão livre verificando suas medidas.

Pode-se dizer que o caráter formal, de conceitos e definições, vinculado à ciência de referência, no caso, a Geometria, é minimizado em comparação com a experiência proposta: exploração e investigação de propriedades nos modelos construídos. De todo modo, identificam-se elementos postos em circulação, que valorizam aspectos dos saberes " $a$ " e "para" ensinar, ligados à compreensão de que:

se articulam de um lado os saberes constitutivos do campo profissional, no qual a referência é a expertise profissional (saberes profissionais ou saberes para ensinar); e, de outro, os saberes emanados dos campos disciplinares de referência produzidos pelas disciplinas universitárias (saberes disciplinares ou saberes concernentes aos saberes a ensinar) (BORER, 2017, p. 42). 
As representações indicam que o ensino da geometria nas classes primárias belgas pautava-se sobre o estudo dos corpos geométricos, e os processos de ensino se davam pela ação intuitiva da criança direcionada pelo professor, que os faz observar as propriedades das figuras geométricas a partir de modelos:

os alumnos os observam, e o professor lhes faz compreender os termos; ensina-lhes as noções de grandezas, da sua comparação, da proporção, da symetria, da equivalência. Os teoremas mais importantes são demonstrados por exercícios intuitivos (REIS, 1892, p. 382).

Além dos passos, Reis (1892) fornece um programa para o ensino de modelos geométricos belga compreendido em cinco anos de duração. Todo o ensino parte da observação de uma figura geométrica espacial, e o processo do qual se deriva esse ensino, segue conforme uma marcha analítica, ou seja, do todo para as partes, remete-se "a atividade de decomposição através da qual distinguimos os diferentes elementos que compõem um todo” (TROUVÉ, 2008, p. 20).

Cada novo elemento colocado ao ensino segue esse processo do todo para as partes, e a partir desse, novos conteúdos são colocados à discussão. Como exemplo, apresenta-se parte do programa dedicado ao segundo ano:

O cubo. Análise. Desenvolvimento e construção (Ver desenho e trabalhos manuais).

O prisma (paralelepípedo (esta palavra difícil não deve ser empregada no primeiro grau) retângulo. Análise) Comparação com o cubo. Desenvolvimento. Construção (Ver desenho e trabalhos manuais).

O quadrado e o retângulo. Intuição. Comparação. Mediana, diagonais. Ditados geométricos. Construções (Ver desenho e trabalhos manuais)

Linhas retas, faces e linhas paralelas, perpendiculares, verticais, horizontais e oblíquas. Objetos comuns. Ditados geométricos. Construção (Ver desenho e trabalhos manuais).

O ângulo reto, o ângulo agudo, o ângulo obtuso. Intuição. 
Comparação. Os ângulos nos objetos comuns. Ditados geométricos. Construção (Ver desenho e trabalhos manuais).

O triângulo. Triângulo a 3 e a 2 lados iguais, a 3 desiguais, triângulo retângulo, triângulo de ângulos agudos, de ângulos obtusos. Intuição. Análise. Comparação. Objetos comuns que tenham essas formas. Ditados geométricos. Construção (Ver desenho e trabalhos manuais).

Medidas de linhas retas (Ver sistema métrico). Sua divisão em 2, 4, 8, $3,6,9,5,10$ partes iguais.

(REIS, 1892).

Pode-se observar que o ensino no segundo ano parte pelo estudo do cubo e do prisma, de forma geral, de observação, desenvolvimento e construção desses sólidos. Posteriormente deriva-se das partes constituintes do cubo e do prisma, suas faces, sejam elas quadradas ou retangulares. O estudo das faces é proposto segundo a intuição, comparação, reconhecimento de suas propriedades (mediana e diagonais), além de ditados geométricos e construções. Na sequência, propõe-se que se estudem as linhas que compõem tais figuras, também sob suas propriedades e na execução de ditados geométricos e construções. O ensino dos ângulos e triângulos, que seguem na mesma direção, de intuição e comparação é precedido dos ditados geométricos e suas construções.

Como dito anteriormente, o método intuitivo é o cerne das mudanças pedagógicas em finais do século XIX. Propõe uma ruptura ao tradicional, caracterizado à memorização, verbalização, reproduções mecanizadas, etc. Neste método de renovação pedagógica, o toque, a observação, a experimentação possuem papel fundamental. Os objetos possibilitam um papel ativo nas crianças, rompendo com o tradicional. No que diz respeito à marcha do ensino, o método intuitivo, baseado nas orientações e estudos de Pestalozzi, sugerem um ensino do conhecido (as figuras espaciais) para o desconhecido (particularidades das figuras planas), do concreto (os modelos produzidos) para o abstrato (definições), do simples para o complexo (de acordo com a compreensão da criança), tal como posto em circulação por Reis (1892). 
E nessa marcha analítica, que exprime o modo de como o professor deve direcionar o ensino, é possível inferir que na representação de Luiz Reis (1892) sobre o ensino primário belga, dentre os saberes que o professor deve se apropriar para ensinar geometria estão os próprios conteúdos, as figuras geométricas espaciais, planas e suas propriedades. Mas além desses, estão as orientações sobre os saberes que o professor deve dispor para ensinar, seja por meio dos trabalhos manuais, do desenho, das medidas e/ou do ditado geométrico.

Como se observa no excerto anterior de Reis (1892), em diversos momentos do programa as menções "Ver desenho e trabalhos manuais", "Ver sistema métrico" ou somente "Ver trabalhos manuais" são inseridas ao final de cada ponto de estudo, usualmente acompanhado da palavra "construção". Tais expressões são utilizadas com o intuito de que o professor, ao direcionar o ensino, acompanhe o programa de desenho, trabalhos manuais ou sistema métrico ${ }^{16}$ como uma ferramenta de auxílio na construção dos sólidos geométricos, figuras geométricas planas, ângulos e linhas.

No entanto, as indicações são empregadas em momentos diferentes. A orientação ao programa de trabalhos manuais ${ }^{17}$ é dada, geralmente, nos primeiros contatos com os sólidos geométricos como, por exemplo, ocorre com o cubo e o prisma no primeiro ano, e o cilindro e a esfera no segundo ano. Essa proposição provavelmente é devido à proposta desses pontos de intuição, análise da forma, comparação e construção dos sólidos geométricos, sem ainda refinar as suas partes constituintes.

Desse modo, é provável que a menção "ver trabalhos manuais", inserida ao final de cada um dos pontos em que se sugere o ensino das figuras

\footnotetext{
${ }^{16}$ A alusão de que se deva observar o programa de desenho e/ou trabalhos manuais é exposta no ponto 2 fornecido no primeiro ano do programa de modelos geométricos.

${ }_{17} \mathrm{O}$ primeiro contato com a pirâmide é realizado somente no quinto ano e é finalizado com a indicação de "ver desenho e trabalhos manuais". Ainda no quinto ano, o ponto sobre medida de volume dos corpos se menciona o termo "ver trabalhos manuais", provavelmente tal menção se dê pois se tem a proposta de que as crianças construam um prisma triangular e divida em três pirâmides equivalentes, para apreender os conceitos de equivalência de volumes.
} 
geométricas espaciais, incite o professor que utilize das ferramentas dos trabalhos manuais, como com exercícios de modelagem e cartonagem, para que as crianças construam esses sólidos e se familiarizem com suas formas. Ou seja, o trabalho manual atua como um saber para ensinar as formas do cubo, da esfera, do cilindro, etc.

Com referência à segunda menção, "ver trabalhos manuais e desenho", a proposta se aproxima de quando o ensino já segue os passos da marcha analítica e passa ao reconhecimento das partes que compõem os sólidos geométricos. Essa é a referência mais comum, usualmente colocada quando já se teve um primeiro contato com a figura geométrica espacial, e busca-se desenvolver com a criança outras propriedades da figura geométrica, mais delimitadas, como as faces, linhas, ângulos.

Assim, conjectura-se que além do trabalho manual, o desenho também atua como um saber para ensinar tais saberes derivados dos sólidos geométricos já estudados, ou seja, o professor tem no trabalho manual e no desenho, ferramentas para ensinar, por exemplo, os triângulos e seus diferentes tipos com dois ou três lados iguais ou três desiguais, seja na própria construção a partir do desenho geométrico ou da modelagem, recorte, dobradura dessas figuras planas.

Outra ferramenta a se destacar, assim como os trabalhos manuais, o desenho e o sistema métrico, é a utilização dos chamados "ditados geométricos", o sexto passo para o ensino dos modelos geométricos, como já dito, uma vez por semana, os alunos traçam à mão livre figuras geométricas ditadas por seu professor, como Reis o exemplifica:

$1^{\circ} \mathrm{O}$ professor imagina e traça exatamente e de antemão uma figura geométrica relativa às noções ensinadas;

$2^{\circ}$ Elle dicta lentamente cada condição de construção desta figura: posição que deve ocupar cada ponto ou cada linha, direção das linhas, sua extensão, abertura, direção, grandeza dos ângulos, etc.;

$3^{\mathrm{o}}$ os alumnos traçam as figuras dictadas a mão levantada e depressa; 
$4^{\circ} \mathrm{O}$ trabalho terminado, eles verificam a figura por meio do esquadro Weyel ${ }^{18}$ (REIS, 1892, p. 463).

Essa mobilização nos permite compreender que o saber a ensinar, é mobilizado pelos saberes para ensinar, em estreita ligação, de forma que o foco está nas atividades, na obtenção do conhecimento de forma ativa, Reis faz circular que o aluno não aprende um modelo geométrico por meio de suas propriedades e definições, mas que por ter tocado, comparado com outras formas utilizadas no seu cotidiano, que após as experimentações, ao serem ditadas as suas características e propriedades, a criança conseguirá obter êxito em sua construção.

Percebe-se ainda, com as análises das propostas em circulação, uma nova produção de "saberes a ensinar", com uma ordem didático-pedagógica original, contrastante com a organização clássica da disciplina de referência, do plano para o espaço, para uma ordem própria dos tempos intuitivos, do espaço para o plano com os sentidos possibilitando a produção de ideias, iniciando do concreto e ascendendo à abstração.

\section{CONSIDERAÇÕES FINAIS}

Pode-se dizer que Reis coloca em circulação, por meio de seu relatório, o que se espera do professor para o ensino de geometria no final do século XIX: um saber profissional em sintonia direta com as propostas do método intuitivo.

Analisar como se caracterizam os saberes profissionais dos professores vai além de analisar metodologias. O exame no relatório de viagem de Luiz

\footnotetext{
18 "O esquadro de Weyel é um esquadro triangular em madeira, do qual os dois lados do angulo recto são divididos em decímetros, centímetros e milímetros. O meio é ôco e fórma um transferidor. O instrumento substitue vantajosamente uma régua, um esquadro, um duplo decímetro e um transferidor. O professor examina rapidamente o trabalho, com o auxilio da figura, correctamente cortada em uma folha de papel forte: é suficiente estender este molde sobre o traçado dos alumnos" (REIS, 1892, p. 463).
} 
Augusto dos Reis, amparado pelos estudos de Hofstetter e Schneuwly (2017), nos permitiu observar a estreita articulação de saberes a ensinar e saberes para ensinar na concretização desses saberes profissionais ao ensino da geometria escolar.

As propostas sobre o ensino de geometria ao curso primário belga, fornecidas por Reis, versam sobre os modelos geométricos, pautam-se sobre atividades práticas e revelam a necessidade de outros saberes ao professor, para além de saberes advindos propriamente de conteúdos geométricos. O recorte, a modelagem, a cartonagem, dentre outros presentes nos trabalhos manuais, o desenho, as medidas e o ditado geométrico se exprimem como suporte e ferramenta para o professor ensinar geometria, caracterizando uma 'nova' geometria para ensinar.

O desenho também ganha destaque como outro componente necessário para a prática do professor que ensina geometria, em especial, no ditado geométrico e no estudo das figuras planas. E as medidas com um papel de verificação, confirmando e validando as propriedades ensinadas.

As análises das propostas em circulação indicam uma alteração nos saberes a ensinar, uma outra ordem didático-pedagógica é recomendada: a inversão da marcha da geometria plana para a geometria espacial, característica do campo disciplinar da Geometria é imperativa na proposta intuitiva, visto que o concreto, o conhecido da criança prevalece e, assim sendo, a exploração dos sólidos como ponto de partida é uma constante na proposta belga. As mudanças no saber a ensinar articulam-se com a mobilização das ferramentas indicadas como saberes para ensinar, evidenciadas pelas atividades dos trabalhos manuais, de desenho e das medidas. Está em jogo um novo saber profissional para o professor que ensina geometria, uma nova geometria para ensinar.

Luiz Reis tece em seu relatório uma análise comparativa entre a proposta belga e a brasileira, diz que "precisávamos muito imitar tudo isto da Bélgica. Entre nós, faz-se justamente o contrário do que lá se pratica" (REIS, 1892, p. 403), porém como tais propostas são apropriadas pelo Brasil constitui- 
se objeto de investigação para novas pesquisas.

\section{REFERÊNCIAS}

ARAÚJO, Roberta Maíra de Melo. Benedicta Valladares Ribeiro 19051989: formação e atuação. 2010. 221 f. Tese (Doutorado) - Escola de Comunicação e Artes, Universidade de São Paulo, São Paulo, 2010.

BASTOS, Maria Helena Camara. Manual para os jardins de infância: ligeira compilação pelo Dr. Menezes Vieira - 1882. Porto Alegre: Redes, 2011.

BASTOS, Maria Helena Camara. Pro Patria Laboremus: Joaquim José de Menezes Vieira (1848-1897). Editora Edusf: Bragança Paulista/SP, 2002.

BLACKE, Augusto Vitorino Alves Sacramento. Dicionário bibliográfico brasileiro. Rio de Janeiro: Imprensa Nacional, 1899.

BORER, Valérie Lussi. Saberes: uma questão crucial para a institucionalização da formação de professores. In: HOFSTETTER, Rita.; VALENTE, Wagner Rodrigues. (Org.). Saberes em (trans)formação: tema central da formação de professores. São Paulo: Livraria da Física, 2017. p. 173-199.

CARDOSO, Silmara de Fátima. Viajar é ser autor de muitas histórias? Experiências de formação e narrativas educacionais de professores brasileiros em viagem aos Estados Unidos (1929-1935). 2015. 236 f. São Paulo: Tese (Doutorado em Educação) - Universidade de São Paulo, São Paulo, 2015.

CHAMON, Carla Simone. Maria Guilhermina Loureiro de Andrade: a trajetória profissional de uma educadora. 2005. 332 f. Tese (Doutorado em Educação) - Programa de Pós-Graduação em Educação, Universidade Federal de Minas Gerais, Belo Horizonte, 2005.

CHARTIER, Roger. A história cultural - entre práticas e representações. Trad. Maria Manuela Galhardo. 2. ed. Lisboa: Difel; Rio de Janeiro: Bertrand Brasil S. A., 2002.

FONSECA, Nelma Marçal Lacerda. Alda Lodi, entre Belo Horizonte e Nova Iorque: um estudo sobre formação e atuação docentes 1912-1932. 2010. 159 f. Dissertação (Mestrado) - Universidade Federam de Minas Gerais, Belo Horizonte, 2010. 
GONDRA, José Gonçalves. A pedagogia da República: uma leitura do discurso oficial da Revista pedagógica (1890-1896). São Paulo: Feusp, 1996.

GONDRA, José Gonçalves. Apresentação. Dossiê: Viagens de educadores, circulação e produção de modelos pedagógicos. Revista brasileira de educação, n. 22, p. 13-16, 2010.

GONDRA, José Gonçalves. O veículo de circulação da pedagogia oficial da república: a Revista Pedagogica. Revista brasileira de estudos pedagógicos, Brasília, v. 78, n. 188/189/190, p. 374-395, jan./dez. 1997.

HOFSTETTER, Rita; SCHNEUWLY, Bernard. Saberes: um tema central para as profissões do ensino e da formação. In: HOFSTETTER, Rita; VALENTE, Wagner Rodrigues (Org.). Saberes em (trans)formação: tema central da formação de professores. São Paulo: Livraria da Física, 2017. p.113-172.

MATASCI, Damiano. L'école républicaine et l'étranger. Une historie internacionale des réformes scolaires en France 1870-1914. Ens éditions, 2015.

MIGNOT, Ana Chrystina Venancio; GONDRA, José Gonçalves. Viagens de educadores e circulação de modelos pedagógicos. In: MIGNOT, Ana Chrystina Venancio.; GONDRA, José Gonçalves. (Org.). Viagens pedagógicas. São Paulo: Cortez, 2007. p. 7-14.

MIGNOT, Ana Chrystina Venancio; SILVA, Alexandra Lima da. Tão longe, tão perto: escrita de si em relatórios de viagens. Educação em revista, Belo Horizonte, v. 27, n. 01, p. 435-458, 2011.

PIMENTA, Jussara Santos. As duas margens do Atlântico: um projeto de integração entre dois povos na viagem de Cecília Meireles (1934). 2008. 374 f. Tese (Doutorado em Educação) - Programa de Pós-Graduação em Educação, Universidade do Estado do Rio de Janeiro (Uerj), Rio de Janeiro, 2008.

PINTO, Inára de Almeida Garcia. Um professor em dois mundos: a viagem do professor Luiz Augusto dos Reis à Europa (1891). 2011. 259 f. Tese (Doutorado em Educação) - Universidade de São Paulo (USP), São Paulo, 2011.

RABELO, Rafaela dos Santos. Destinos e trajetos: Edward Lee Thorndike e John Dewey na formação matemática do professor primário no Brasil (19201960). 2016. 285 f. Tese (Doutorado em Educação) - Faculdade de Educação, Universidade de São Paulo (USP), São Paulo, 2016.

REIS, Luis Augusto dos. O ensino público em Portugal, Espanha, França e Bélgica. Rio de Janeiro: Imprensa Nacional, 1892. 
RIO DE JANEIRO. Revista pedagógica. Rio de Janeiro: Livraria Classica de Alves \& Companhia, 1895 .

SCHUELER, Alessandra Frota Martinez de.; GONDRA, José Gonçalves. Olhar o outro, ver a si: um professor primário brasileiro no velho mundo (1890-1892). Revista brasileira de história da educação, n. 22, p. 88-114, 2010.

SOUZA, Rosa Fátima. Alicerces da pátria: história da escola primária no estado de São Paulo (1890-1976). Campinas, SP: Mercado de Letras, 2009.

TROUVÉ, Alain. La notion de savoir élémentaire à l'école. Paris: L'Harmattan, 2008.

VALDEMARIN, Vera Tereza. Os sentidos e a experiência: professores, alunos e métodos de ensino. In: SAVIANI, Dermeval et al. O legado educacional do século XX no Brasil. Campinas, SP: Autores associados, 2004.

VALENTE, Wagner Rodrigues. Quando o nacional é internacional. Resenha do livro: L'école républicaine et l'étranger. Paris: ENS, 2015. Revista História da educação, Porto Alegre, v. 20, n. 48, p. 303-306, jan./abr. 2016.

VALENTE, Wagner Rodrigues. Sobre a investigação dos saberes profissionais do professor de matemática: algumas reflexões para a pesquisa. Caminhos da educação matemática em revista, v. 6, n. 1, 2016.

VIDAL, Diana Gonçalves. Culturas escolares: estudo sobre práticas de leitura e escrita na escola pública primária (Brasil e França, final do século XIX).

Campinas, SP: Autores associados, 2005.

GABRIEL LUIS CONCEIÇÃO é doutorando em Ciências pela Universidade Federal de São Paulo (Unifesp), Mestre em Educação Matemática. Professor do Centro Universitário Geraldo Di Biase (UGB) e da Faculdade Sul Fluminense (FaSF).

E-mail: gabrielluis_matematica@yahoo.com.br

(i) http://orcid.org/0000-0002-7789-0369

MARIA CÉLIA LEME DA SILVA é doutora em Educação (Currículo) pela Pontifícia Universidade Católica de São Paulo (PUC-SP). Docente da 
Universidade Federal de São Paulo (Unifesp).

E-mail: mcelialeme@gmail.com

(1) http://orcid.org/0000-0001-6029-0490

Recebido em: 18 de outubro de 2018

Aprovado em: 11 de junho de 2019
(c) (i)
Revista História da Educação - RHE
Associação Sul-Rio-Grandense de Pesquisadores em História da Educação - Asphe
Artigo de acesso aberto distribuído nos termos de licença Creative Commons.

